AperTO - Archivio Istituzionale Open Access dell'Università di Torino

Smart city governance: exploring the institutional work of multiple actors towards collaboration

This is a pre print version of the following article:

Original Citation:

Availability:

This version is available http://hdl.handle.net/2318/1685795

since 2019-01-07T11:06:22Z

Published version:

DOI:10.1108/IJPSM-05-2018-0126

Terms of use:

Open Access

Anyone can freely access the full text of works made available as "Open Access". Works made available under a Creative Commons license can be used according to the terms and conditions of said license. Use of all other works requires consent of the right holder (author or publisher) if not exempted from copyright protection by the applicable law. 


\section{Smart City governance: Exploring the institutional work of multiple actors towards collaboration}

\begin{tabular}{|r|l|}
\hline Journal: & International Journal of Public Sector Management \\
\hline Manuscript ID & IJPSM-05-2018-0126.R2 \\
\hline Manuscript Type: & Original Article \\
\hline Keywords: & $\begin{array}{l}\text { Smart city, Institutional work, Collaborative governance, New Public } \\
\text { Governance, Local government }\end{array}$ \\
\hline \multicolumn{2}{|l}{} \\
\hline
\end{tabular}

\section{SCHOLARONE ${ }^{m}$ \\ Manuscripts}




\section{Smart City governance: Exploring the institutional work of multiple actors towards}

\section{collaboration}

\section{INTRODUCTION}

Smart City is one of the most used terms to depict the growing efforts put in devising a strategy for achieving urban growth in a "smart" manner (Caragliu et al., 2011) through innovative and sustainable policies. Many different meanings can be attached to the word smart, resulting in a wide variety of alternative labels, such as intelligent city, knowledge city, ubiquitous city, and sustainable city (Cocchia, 2014). Clearly, the lack of a unique and broadly shared definition of the concept (Angelidou, 2014; Caragliu et al., 2011; Chourabi et al., 2012) has rendered it a "fuzzy" (Caragliu et al., 2011, p. 67) and an ambiguous leitmotiv (Vanolo, 2014). Hence, consensus on the meaning of this concept and agreement regarding whether such reform can meet desired expectations or create a utopia (Anthopoulous, 2017; Grossi and Pianezzi, 2017) are far from being achieved.

The element of Information and Communication Technology (ICT) was incredibly relevant in the early definitions of a smart city (Bifulco et al., 2016; Caragliu et al., 2011). Although, according to some studies, this dimension remains central (Mora et al., 2017), the interpretation of the elements enabling smartness has evolved, ranging from the relevance of the ICT dimension (Bakici et al., 2013) to the inclusion of human capital and education (Berry and Glaeser, 2005; Fu, 2007). Consequently, the idea of a smart city can find its core components in the creation and connection of technology infrastructure, human capital and social capital to enhance sustainability and improve the quality of life (European Parliament, 2014). The integration of three dimensions, technology, human resources and governance, may be expected to contribute to the smartness of the initiatives realized by a city (Meijer and Bolivar, 2016). In this context, although governance is recognized as a key factor, its role in the field of smart cities is underexplored (Bolivar, 2015; Pereira et al., 2017) and the meaning of smart city governance is not uniquely defined (Albino, 2015; Pereira et al. 2017; Scholl and Scholl, 2014; Šiugždinienè et al., 2017).

Reviewing the literature on smart cities, Meijer and Bolivar (2016) found out that a smart city may be a city with smart collaboration in which the smart city governance appears to rely on participatory mechanisms and collaboration among several actors (Caragliu et al., 2011; Kickbusch and Gleicher, 2012; Pereira et al., 2017). The literature supports the idea that smart governance may comprise several different aspects, among which participation in decisionmaking (Giffinger et al., 2007) and use of internal and external resources (Šiugždinienè et al., 
2017) play a key role to foster innovation and improvement. These considerations recall the concept of collaborative governance (Ansell and Gash, 2008; Emerson et al., 2012) in line with the principles of the recent reform movement known as New Public Governance (NPG) (Osborne, 2010), which emphasizes collaborative and participatory forms of governing to improve public policy-making and public service delivery (Torfing and Triantafillou, 2013). Indeed, a collaborative governance model has been considered a tool to support smart cities and, simultaneously, one of its key components (Nam and Pardo, 2014; Pereira et al., 2017) since the collaboration among different functional sectors and actors (government, business, academics, non-profit and voluntary organizations, and others) contribute to the success of city initiatives (Eger, 2009). However, how and why collaborative governance may be constructed and work in the context of a smart city are underexplored questions. Hence, this study seeks to contribute to this ongoing debate from a public management and governance perspective examining the institutional work carried out by multiple actors in constructing collaborative governance (Emerson et al., 2012; Lawrence et al., 2013) in the context of a smart city. This inquiry is made needed by the fragmented understanding of smart city governance and its underexplored connection to collaborative governance. Although multiple actors are expected to play a key role in designing and implementing smart initiatives and their role is essential to build collaborations (e.g. Bolivar, 2015), the current body of knowledge lacks proper analysis of actors' works in the context of smart city. The ambition of this study is thus to investigate how and why different types of institutional work carried out by multiple actors may influence the way in which a specific model of governance can be constructed and work in the context of a smart city, going beyond rhetoric and management fashions. Indeed, the investigation of the nature of the institutional works carried out may significantly contribute to understand the extent to which smart policies may be implemented successfully or not through collaborative dynamics (Cloutier et al., 2015). To this aim, the concept of institutional work is useful insofar as it enables the explanation of the observed model of governance in the smart city under investigation (Ryan et al., 2002) by investigating the work of multiple actors and recognizing their efforts (Hwang and Colyvas, 2011), and it generates initial reflections useful for bridging the concepts of smart city governance and collaborative governance.

An empirical analysis was carried out in Italy, a country that has paid increasing attention to smart policies in recent years (Vanolo, 2014). In particular, the case of a city in the north of the country, Turin, was explored because it has put increasing efforts into becoming smart in the last few years, receiving several awards in recognition of these attempts (EY, 2016), and, especially, it has devoted particular attention to build collaborations and support participation. 
Thus, the city's strong orientation towards smartness over time and its multiple experiences in projects and collaborations make the case relevant for achieving the research purpose.

The paper is structured as follows. The next paragraph reviews the key concept of governance in a smart city and explains the framework of analysis by discussing the concepts of collaborative governance and institutional work. It proceeds with illustrating both the setting where the research was conducted and the method adopted. Then, it presents and discusses the findings of the empirical analysis. Final remarks highlight the implications and contributions of the research.

\section{SMART CITY GOVERNANCE}

\section{The debate}

Governance is considered a key element that influences and, simultaneously, is influenced by smart city initiatives in a two-way relation (Chourabi et al., 2012). Governance thus becomes one of the assets of a smart city model (Bakici et al., 2013; Giffinger et al., 2007), assuming the connotation of being smart. The expression smart governance has attracted growing scholarly attention, being identified as one of the key dimensions of a smart city with smart economy, smart mobility, smart environment, smart people and smart living (Caragliu et al., 2011; Giffinger et al., 2007; Lombardi et al., 2012; Paskaleva, 2011). However, its meaning is a source of confusion and requires further analysis (Šiugždinienè et al., 2017).

Initially, the concept of smart governance was primarily linked to the use of ICT, used as a synonym for e-government (Pereira et al., 2017; Scholl and Scholl, 2014), and it has been considered enhanced by the use of open data (Bartenbenger and Grubmuller-Regent, 2014). This sectorial approach contrasts with a broader perspective, whereby smart governance has been considered a form of governance comprising principles and capacities appropriate for coping with the current challenges of society (Scholl and Scholl, 2014). This fragmented and continuously evolving debate on smart governance challenges the elaboration of a widely accepted definition of the concept, even reflecting the criticalities in defining the meaning of smart city.

A recent literature review on governing the smart city noted that an approach to define smart city focused on governance interprets a smart city as a city with smart collaboration (Meijer and Bolivar, 2016), where smart collaboration refers to interactions between various stakeholders in the context of smart city initiatives. Specifically, this recent review noted various types of smart governance, which are contrasting approaches that contribute to undermine the understanding of the topic. The first type of smart governance is the government 
of a smart city with no need for transformation or change; the second type implies the need for change in the decision-making process, which should become a smart decision-making; and the third type leads to the creation of a smart administration, calling for the most significant transformation and implying the involvement of and collaboration among multiple actors. Although these three approaches are all undermined by blurred definitions of the attribute "smart", we assume that among them the last approach can be the most suitable for supporting the realization of smart city initiatives and thus deserves further investigation.

In this regard, the ability to build collaboration and partnerships is often referred to as a component of smart city governance and a key to have success (Chourabi et al., 2012; Coe et al., 2001; Moss Kanter and Litow, 2009; Nam and Pardo, 2014; Scholl and Scholl, 2014). A smart city needs collaboration across departments and with communities (Batagan, 2011), making various stakeholders involved in the decision-making process (Albino, 2015), with particular attention paid to the relationship between city government and its citizens (Giffinger et al., 2007; Lombardi et al., 2012; Paskaleva, 2011). Thus, the smartness of governance may be intended to be built on the participation of multiple actors and on collaboration with public and private organizations and knowledge institutions (Bakici et al., 2013) finalized to realize smart city initiatives. Smart governance has been recently defined as a system that operates in an efficient and effective manner in a rapidly changing environment using internal and external resources to foster innovation and improvement in providing shared values (Šiugždinienè et al., 2017). Accordingly, smart city governance is expected to include elements of external collaboration, internal coordination, and partnerships (Batagan, 2011; Caragliu et al., 2011; Giffinger et al., 2007), in line with NPG trend in the public sector which has stressed the relevance of collaborative and participatory approaches (Torfing and Triantafillou, 2013) and the ability of cross-sector collaborations to remedy complex public problems (Bryson et al., 2006).

Hence, the existing debate on smart governance appears to recognize its strong reliance on collaborations and partnerships, suggesting that a city needs a collaborative governance to become smarter (Nam and Pardo, 2014; Pereira et al., 2017). Specifically, Nam and Pardo (2014) have analysed collaborative governance as one of the factors supporting a smart city, considering collaborations as one of the metrics to assess a smart initiative, while Pereira et al. (2017) have focused on the role of ICT to promote collaborative governance in the context of smart city.

However, in addition to the confusing conceptual approaches to smart city governance, the debate on the topic lacks empirical investigation providing insights into the functioning of 
smart city governance and its connection with specific models, as collaborative governance, since the claimed relevance of collaborations and partnerships is not corroborated by adequate empirical analysis. The governance questions remain unanswered (Bolivar, 2015), but represent relevant issues since implementing an innovative idea, such as the idea of a smart city, is different from its ideation (Brorström, 2015).

The general purpose of this research is thus to contribute to the understanding of smart city governance from a public management and governance perspective. This becomes an empirical inquiry leading to investigate why and how a collaborative governance model (Emerson et al., 2012) can be constructed and work in the context of a smart city. The ambition of the study is to explain this context by investigating the work carried out by multiple actors. Indeed, the complexity of smart city initiatives poses challenges in terms of governing the new modes of public policy design and implementation which call for a network of different actors and influence then governance structures.

National and international actors, the local government, local associations, not for profit organizations, community representatives and citizens, lobbies and private organizations are all categories of actors who may play a role. These multiple actors have specific interests and know-how and can differently contribute to smart initiatives and collaborations. For instance, governments may be regulators, funders and/or coordinators of smart city initiatives (Bolivar, 2015). Citizens may be involved directly in the work of government in response to their call for more transparent, accountable and effective administration. Their involvement can reshape the governance of a city through participatory mechanisms as the living labs, which keep the users continuously involved in making better products and services (Paskaleva, 2011). These processes of democratization and empowerment can recognize to the citizens the opportunity to express opinions on policies, participate in boards and public hearings (Šiugždinienè et al., 2017; Sorensen and Torfing, 2012), shaping collaborative dynamics and actions.

These multiple actors can shape then the governance structures by being an active component in the process of designing and implementing smart city initiatives and policies. In this context, their efforts and works can make the difference in the realization of successful collaborative dynamics to make the city smart. Thus, it becomes crucial to study the work on the part of a wide range of actors. Nevertheless, little attention has been given to the type of work demanded of and engaged in by those multiple actors in the design and enactment of smart city policies and initiatives. The current study thus employs the notion of institutional work (Lawrence et al., 2013) that can recognize the distributed and pluralistic nature of smart city efforts, where a wide spectrum of actors shares their design and implementation and none 
of them has complete control over outcomes (Cloutier et al., 2015). The research questions of the current study can be formulated as follows: why and how can a collaborative governance model be constructed to make a city smarter? Why and how do different institutional works engaged by multiple actors influence the collaborative governance of a smart city?

The next sub-sections will illustrate, respectively, the concepts of collaborative governance and institutional work on which the research relies to address its questions.

\section{A collaborative governance approach}

Collaborative models of governance in the public sector have attracted growing attention worldwide (Bommert, 2010; Christensen and Lægreid, 2007). Several definitions and interpretations of collaborative governance have been developed, ranging from a stricter approach (Ansell and Gash, 2008) to a broader construct (Emerson et al., 2012). While the first approach specifies the actors involved in such arrangements and the key features to be respected, Emerson et al. (2012) elaborated on a broader definition of collaborative governance, widening its boundaries and including several typologies of actors, processes and structures. These scholars defined collaborative governance as "the processes and structures of public policy decision-making and management that engage people constructively across the boundaries of public agencies, levels of government, and/or the public, private and civic spheres in order to carry out a public purpose that could not otherwise accomplished" (2012, p. 2). This broader interpretation allows us to investigate in a comprehensive manner the approach adopted to make a city smart by involving public, private and civic sector actors to realize a smartness-orientation.

According to the integrative framework developed by Emerson et al. (2012), the general system context is influenced and determined by political, socioeconomic, legal and environmental issues that can create opportunities (or constraints) to build collaborative governance, thus explaining the reasons why the construction of such model can be encouraged (or not). For instance, lack of resources, influence of specific policies or regulations may characterize the context and influence the construction of collaborative dynamics. Indeed, the system context determines specific drivers of collaborative governance, which can help collaboration dynamics to occur. Potential drivers are represented by the presence of leaders who persuade the actors and support collaboration, by the interdependence among actors that strongly motivate them to collaborate to be able to solve a problem, and by the presence of specific incentives, such as the need for resources, or uncertainty regarding how to manage a change. 
These drivers may activate collaboration dynamics when key actors work together to identify shared interests and communicate them to make agreed-upon decisions. Actors may activate a shared decision-making in order to decide a plan of actions, evaluate and discuss ideas and projects before deliberating them. In this context, it is important to pay attention to two factors that can support these dynamics, namely the existence of shared motivation and capacity for joint action. In the first case, a reciprocal knowledge of the actors, who thus develop the ability to understand and respect one another, may create legitimacy and commitment, thus motivating the actors towards similar goals. Then, the development of collaboration is rendered feasible by a capacity for joint action. This is determined by several factors, such as process protocols and organizational structure; human resources and skills, such as lead actors, shared knowledge, skills and expertise; and more proper technical issues, such as funding, time, and technical and logistical support. By working together in an interactive manner, these collaboration dynamics result in collaborative actions such as the definition of policies, regulations, projects or agendas.

The present research uses this model for collaborative governance as a conceptual tool to enhance the analysis of the case. The chosen framework allows us to identify the key actors involved in the context of a smart city, to illustrate the context factors that can encourage the construction of a collaborative governance and its main characteristics. However, in order to understand how and why the collaborative governance can be constructed and work, the analysis explores the role of the key actors using the theoretical construct of the institutional work.

\section{The actors' institutional work in a collaborative framework}

The study of institutional work has become an attractive approach in recent years (Lawrence et al., 2013) as an extension of traditional institutional concerns useful in investigating the role of actors in creating, maintaining or disrupting institutions (Lawrence et $a l ., 2011)$. Institutionalist theorists have increasingly paid attention to investigate how and why actors transform, institutionalize or deinstitutionalize institutionalized practices (e.g., Seo and Creed, 2002). The concept of institutional work describes the practices of individual and collective actors who put physical or mental efforts into intentionally achieving their final goals (Lawrence and Suddaby, 2006; Lawrence et al., 2011). The study of institutional work can investigate how institutional work occurs, who performs institutional work, and what constitutes institutional work (Lawrence et al., 2013). Specifically, the concept of institutional 
work allows the investigation and understanding of how and why actors work and with what effects.

The current research applies the concept of institutional work to analyse how multiple actors contribute to build a collaborative governance in a smart city. Indeed, actors are engaged in different works and each type of institutional work may have different features, which are important in understanding how and why the various activities engaged in by actors influence adoption and implementation of reforms (Cloutier et al., 2015). In light of the various typologies of institutional work, three primary types of institutional work designed to create an institution (Lawrence and Suddaby, 2006; Perkmann and Spicer, 2008) may be political, technical and cultural work, where the type of work each actor is engaged in can be influenced by the actor position in the field.

Political work refers to the development of rules and to the assignment of specific roles and tasks to certain actors, aligning their interests with practice. Political work involves recruiting relevant actors into coalitions and networks creating the support for a practice (Perkmann and Spicer, 2008). Politicians are the perfect example of actors who specialize in this work. In the context of smart city, politicians are expected to be among the main actors involved given their role in the local and central governments and in international institutions. Political work is expected to be carried out by those actors in order to develop new rules and set tasks suitable for addressing the system context conditions, as the need of environmental policies or the call for resources, and shaping the context drivers for innovation towards the achievement of their interests, as the assignment of specific tasks to actors in order to create reform supporters and make them lead the process of implementation of smart policies. Further, the assignment of roles and responsibilities may contribute to create the needed capacity for joint action, through the establishment of proper institutional and procedural arrangements.

Technical work creates then the link between what is new and what was previously present and educates other people towards the implementation of new practices. Technical work supports the implementation of management practices, for instance, by creating accepted standards or models, and educating participants (Perkmann and Spicer, 2008). The related skills are mostly concentrated among consultants, academics and other professionals (Perkmann and Spicer, 2008) who have expert competences to facilitate the new practices. In the context of smart city, several across-sector actors may be involved in order to share their resources and know-how to stimulate the development and implementation of smart initiatives and collaborations, thus facilitating the creation of capacity for joint action. 
Finally, cultural work should intervene to construct identities, change norms, and construct networks with other organizations to render new practices normatively desirable, and frame the practices in order to make them appeal to broader audiences (Benford and Snow, 2000). The cultural work is particularly relevant to make the smartness-orientation accepted by the multiple actors and create shared motivation towards it. Indeed, a shared and clear understanding of what to do and why is the basis for the development of collaborative dynamics aiming at the achievement of the same shared goals.

The three different types of work are expected to be needed and at work in parallel in order to make possible the realization of a collaborative governance, addressing context factors and managing the consequent drivers towards the establishment of conditions suitable for supporting collaborative dynamics and implementing "smart" actions. Indeed, although the different works are analysed separately, it is important to consider them together in order to investigate their interconnection and their effects on collaborative governance in the context of smart city. The political work is required to start the establishment of collaborative dynamics towards smart city policies but it will need an adequate technical work on the part of the involved actors in order to guarantee the needed capacity for action to translate into practice the planned policies. However, human resources, skills, technical and institutional arrangements will not be effective without a shared understanding of the goals to achieve and a motivation towards them built through proper cultural works.

The lens of institutional work is thus powerful because it allows to point out who are the actors and which are their works influencing the governance of smart city and contributing to build collaborative governance.

\section{RESEARCH SETTING AND METHOD}

An in-depth analysis of the case of Turin, a smart city in Northern Italy, has been carried out. This single case study is used to explain the observed model of smart city and generate initial reflections on the connection between smart city governance and collaborative governance through the theoretical lens of institutional work (Ryan et al., 2002). In order to reach this research purpose, the city under analysis was purposefully selected because it was considered relevant and interesting for several reasons.

First, Italy is a country "fully committed to smart urban policies" (Vanolo, 2014, p. 884), and the city selected has particularly been recognized as an example of a smart city. The crisis of the industrial model on which the city was built has promoted the investments in different sectors, as ICT, tourism, and education, supporting an attitude towards smartness (Crivello, 
2015). In this context, since the beginning of 2010s, the city has paid attention to develop smart policies and strategies. It won the Italian Smart City prize (2014) and, in recent years, ranked at the top of the Smart City Index in Italy (EY, 2016). The apparent success of the city over the years is a reason to investigate it (Pereira et al., 2017) because it can be considered a signal of the lasting attention paid by the city to smart city initiatives. As a consequence of these longlasting efforts, the governance model is expected to be structured enough to make the case relevant for the research purpose. Second and more specifically, constant efforts have been made to reinforce and improve the smartness of Turin in the last few years by inter-institutional collaboration (Vanolo, 2014) and internal collaboration (Michelucci and De Marco, 2017). This emphasizes the relevance of collaborative mechanisms. Further, the local government has established ad-hoc foundations and partnerships in order to support the realization of smart city initiatives. This clearly show the multiplicity of actors involved and thus makes the case suitable for achieving the research purpose.

The study integrates document analysis and interviews (Yin, 2013). The research process began with the analysis of publicly available information on the website of the municipality of Turin, on the portals of the other organizations involved in the smart city initiatives, as foundations and public-private partnerships, and on the ad hoc websites dedicated to these initiatives. Then, the researchers investigated the information included in official reports and documents describing the initiatives undertaken to make the city smart.

Based on the information stemming from the document analysis, semi-structured interviews were conducted with the actors engaged in making the city smart. Several institutions and organizations were involved according to an information-oriented process (Flyvbjerg, 2006), which allowed the identification of experts capable of elucidating the role played by each of them in the smart city governance model. First, the interviews involved the municipality of Turin. Then, based on the snowball technique, other informed people were identified, contacted and interviewed to represent the key actors involved in making the city smart.

The actors interviewed represented the points of view of politicians and managers of different units inside the municipality, and specifically: the main unit devoted to European funds, innovation and smart city (referred to as "smart city unit"); another sector unit involved in smart city initiatives; and the organizational innovation unit of the municipality. In addition, key actors outside the municipality were involved, as public-private partnership, association and foundation in charge of smart city initiatives. A list of the actors interviewed is presented in Appendix 1. 
The face-to-face, semi-structured interviews occurred at the interviewee's work place from March to May 2017 and lasted an average of 70 minutes. The interviews were designed to explore the institutional works performed by different actors in order to find out how and why collaborative governance can be constructed. Therefore, questions were developed starting from the elements of the framework of analysis and explored the dimensions of a collaborative governance model, through the opinions of multiple actors, who were always asked to comment on who were the involved actors and which activities they performed. The general outline of the interviews is reported in Appendix 2.

To avoid biases and reinforce the reliability and accuracy of the research, the interviews were digitally recorded, transcribed, and then translated into English. Interviewees' words were analysed through cyclical readings, relevant issues were identified and categorized according to the dimensions of the framework of analysis. These findings were compared and contrasted with the information stemming from the analysis of the documents.

The reliance on a single case study may represent a limitation of the research. However, it focuses on a specific case for which it provides deep insights paving the way for future elaboration and larger case studies.

\section{COLLABORATIVE GOVERNANCE IN PRACTICE}

By relying on the framework of collaborative governance (Emerson et al., 2012), this section illustrates the context factors and drivers that have encouraged the construction of a collaborative governance in Turin (first subsection) and depicts its main characteristics (second subsection). Hence, this analysis allows us to illustrate the approach adopted to make Turin a smart city and to identify the key actors involved.

\section{The beginning of the smart discourse: system context and drivers}

Environmental pressures characterized the beginning of the smartness orientation in Turin. Indeed, the city became committed to a smart philosophy in 2009 when the local government signed the "Covenant of the Mayor", an initiative supported by the European Commission (EC), and then approved the Turin Action Plan for Energy (TAPE), which focused on reducing the city's $\mathrm{CO}_{2}$ emissions. The pressure exerted by the EC led to the creation of a normative framework according to which investing in smart and, specifically, sustainable policies began to be considered relevant by the central and local governments, influencing the policy and regulatory framework. Specifically, the EC influencing role is evident since the 
actors in Turin local government have often considered the Commission's drafts when deciding what to do and where to invest:

"We have the task of looking to Europe, to the new trends of innovation and policy, and trying to interpret them at the local level" (Municipality- Interviewee B).

Connected to the new policy framework, several European and national funding initiatives, such as the Ministry of Education's projects "Smart Cities \& Communities" and "Social Innovation", were launched in the field of smart city. Consequently, the local government attempted to join those projects to address its need of resources. Hence, these resource conditions and both European and national policy frameworks established the base upon which Turin smart city was born and grew. Indeed, according to the existing political system, the local government was influenced by the decisions of national government and European Commission regarding the allocation of resources and the policy framework within which it was opportune for the local government to operate.

Consequently, since both the policy framework and the funding initiatives explicitly called for the creation of collaborations and partnerships, the construction of collaborations became tightly linked to the implementation of smart initiatives. This approach was partly facilitated by the city council members' previous participation in European projects, which facilitated collaboration and partnerships with other experts and organizations to realize joint projects to make cities smarter.

"We come from that world (of joint projects). We know each other ... it is easier" (Municipality- Interviewee D).

In addition, the local government has paid increasing attention to the smartness discourse, enlarging its approach to the topic, in response to increasing political and societal pressures (Emerson et al., 2012). Consulting agencies have begun to produce ad hoc rankings aimed at measuring the smartness of cities and thus indicating who can be considered smart, putting pressure on the local government interested in winning the legitimacy game. Moreover, the society has become increasingly aware of the relevance of sustainable development, calling for more inclusive, transparent, and sustainable administrations. The analysis of the interviews confirms these considerations and notes how investing in a smart city has been considered necessary to address current challenges:

"There is a strong financial crisis, a weak public budget (...), investing in becoming a smart city can be considered an answer to social challenges so complex that a public administration cannot solve them anymore by itself' (Municipality- Interviewee A). 
Importantly, this reveals that investing in becoming a smart city has been considered synonymous with investing in building relationships with actors outside the public administration. Hence, a collaborative governance model appears to be intrinsic to a smart city. Further, it appears to be the solution to problems that cannot be solved otherwise, signalling prior failures to address those issues.

This context has determined several drivers providing the impetus for smart city initiatives in Turin (Emerson et al., 2012). As the context analysis previously noted, resource needs strongly determined the instrumental interest in smart city initiatives, and funding opportunities and grants thus represented crucial incentives to be committed to smart city projects. Since in the majority of cases funding opportunities were strongly interconnected with the need to create partnerships, a regime of collaborative governance was facilitated. Accordingly, the local government joined several European projects and networks to obtain the necessary resources to translate into practice the initial ideas and to learn from the other contexts how to become smarter.

Actors in the smart city unit of the city, which is the internal coordinator of smart city initiatives, have also perceived the need to rely on multiple actors outside the public administration to identify the forces to address current challenges. In particular, the interdependence was mostly perceived at the local level, although several criticalities may be detected in this regard. For example, public managers and politicians recognized the interdependence between local government and local public utilities, whose involvement is crucial for innovating public services but represents a key challenge. However, as stated by the actors interviewed, public utilities often lack incentives to innovate and thus demonstrate resistance to change.

Another key driver recognized by the actors interviewed was represented by the need to rely on an identified leader who could support the realization of smart city initiatives. To develop a commitment to the smart city vision, in fact, the local government established in 2011 an ad hoc foundation to which it designated a specific role and responsibilities. This foundation comprised a team of public organizations and institutions, universities, private companies, and companies jointly owned by the city and various associations. It was designed to (a) elaborate on and support projects aimed at training citizens and organizations towards a sustainability culture; (b) identify actions aimed at contributing to the improvement of the quality of life, economic development and environmental protection; and (c) research and promote the rationale for the management of local energy resources using innovative approaches. Thus, the foundation was expected to play a leadership role in facilitating 
partnerships and collaboration between public and private sectors and represent the link among key actors to contribute to the realization of a smartness-oriented mission by providing the support for initiating collaborative efforts. In addition, a public-private partnership born in 2003 by the initiative of national and local institutions and private companies and recognized as a key player (Foundation Alfa) coordinated the activities related to the design of a smart city's master plan to be implemented.

\section{Shared motivation and capacity for action}

As emerged from the previous discussion, the local government, ad hoc foundations, and public-private partnerships played a role in the path towards making Turin smart. These various organizational actors represent diverse interests that are integrated in an attempt to define and implement smart city policies and projects. The analysis of the participants in these initiatives indicates the key features of a collaborative governance model. Firstly, the interviews indicate that the actors attached various meanings to the concept of a smart city, ranging from a social perspective underlining the necessity of addressing societal challenges to a technological perspective whereby technological innovations are expected to make the city smarter. The discrepancies in the definitions of common terminologies and purposes have resulted in the realization of numerous different projects and activities, each of which involved diverse actors and represented a specific declination of the broader mission.

"What does smart city mean? Very difficult question! It is a broad theme” (PPP Interviewee G).

Accordingly, smart city governance appears complex and fragmented. Actors have started to collaborate to identify shared interests and develop shared objectives by elaborating master plans for making the city smarter. Then, ad-hoc projects have been elaborated on specific issues within the broader vision of the smart city, involving different actors and assuming diverse connotations each time. These dynamics have been affected by difficulties in building widespread motivation and diffuse capacities for joint action.

In addition, the public sector in Italy is characterized by a bureaucratic structure that is difficult to change. Conversely, smart city initiatives and policies often require diffuse changes that may be impeded by local resistance. Notably, resistance exists within the public administration because the last political changes have not created widespread commitment to the new political vision of a smart city. The work of the current government has not yet provided a strong shared basis for developing new initiatives, and some tensions have emerged 
between politicians and managers and municipality' employees previously involved in the implementation of such initiatives.

The collaboration between the local government and other organizations has also been challenging. Different entities have different interests and purposes but are interdependent, and their synergy may be important in developing smart innovative projects or initiatives. In this context, the municipality's unit devoted to the smart city has attempted to engage with other local actors, but with difficulties, particularly in the case of public utilities because of the lack of incentives to innovate from the point of view of public utility organizations. A shared motivation has not been built:

"The motivation, both internal and external, is a big challenge" (Municipality Interviewee B).

Finally, inappropriate capacities for joint action have been discussed. Indeed, to create collaboration to develop new policies, a new capacity for action should be developed. Procedural and institutional arrangements, leadership, knowledge and resources are four necessary elements that guarantee the capacity for joint action (Emerson et al., 2012). These imply the need for formal and informal rules and protocols, adequate structural dimensions at both intra-organizational and inter-organizational levels, appropriate resources and skills.

The analysis of the empirical material indicated, conversely, the lack of clear procedural and institutional arrangements. At the intra-organizational level, informal rules and procedures have often prevailed. This blurs the boundaries of responsibilities, renders the accountability mechanisms unclear, and weakens the measurement of the connected performance.

The organizational structure of the local government and the ad hoc unit devoted to smart city projects were inappropriate for handling the broad and variegated approach to a smart city.

"The city is so large, it has so many problems that the smartness of the city is not the issue on which the whole organization can be built" (Municipality- Interviewee C).

Despite efforts to make the role of the internal smart city unit transverse and horizontal, the results do not meet expectations.

In addition to this smart city unit, other units of the municipality may be involved from time to time according to the topic of the specific project, and a variety of external actors come in contact with the municipality but constantly employ different approaches:

"The relationships with the municipality change continuously. It is a difficult aspect. There is not a unique valid or standardized model. We work in an ever-evolving context, and we need to reinvent ourselves every time” (PPP- Interviewee G). 
Thus, in this context, leadership appears fragmented and the lack of a uniform interpretation challenges a shared commitment. Generally, once the actors begin to work together, they know one another and can develop a mutual trust that leads to building a sound network of relationships for the future. In its turn, trust paves the way to mutual understanding, which builds legitimacy and, therefore, commitment. This process seems to be difficult in practice.

"Sometimes actors speak different languages and the geographic proximity is not enough to understand each other" (Municipality- Interviewee C).

Further, in a collaborative governance model, each partner brings distinctive knowledge, as recognized by the actors interviewed. However, the difficulties in understanding one another render it difficult to identify the knowledge to share. As a consequence of the resistance and low level of trust internal and external to the administrations, the existing knowledge is often not recognized, although there have been previous investments in training public managers regarding smart city policy design and implementation; thus, the lack of its appreciation constrains collaboration's potential.

As a result of the dynamics previously discussed, various types of smart initiatives and actions have been realized. These actions can produce intermediate or final results and may be classified according to whether they have been realized by individual participants following agreed-upon tasks (first type) or whether they have been realized by multiple actors together (second type). Concerning the first type, smart city initiatives have been mainly realized through European partnerships funded by EC, thus involving the municipalities in concert with other national and international public and private organizations. On these occasions, each partner realized the tasks agreed to at the European level but in a national context. Concerning the second type, the municipality worked with the other actors to organize workshops and seminars at the local level and to define policy agendas and carry out sectoral projects and experiments.

Appendix 3 summarizes the characterizing elements of collaborative governance in the case investigated, in order to better understand then the influence of institutional works by multiple actors on the smart city governance.

\section{THE INSTITUTIONAL WORK OF MULTIPLE ACTORS}

As emerged from the previous discussion, multiple actors played a specific role in contributing to design and implement smart city initiatives in a collaborative governance model. In particular, they performed their institutional work in a context characterized by resource constraints and calling for meeting economic, environmental and social imperatives. 
Firstly, the European Commission and, then, the national government performed a significant political work in promoting policy frameworks oriented towards a smart city discourse and tried to make them desirable emphasizing the relevance of those kinds of intervention for addressing environmental and societal issues (cultural work). In response to these works, the local government of Turin elaborated a vision attempting to build a normative environment favourable to a smart city (cultural work). According to the information reported on the official website dedicated to the smart city project, the ambitious vision was that the local government would become smart by generating high technology while respecting the environment, reducing $\mathrm{CO}_{2}$ emissions, and improving the quality of life. Technology, environment and society were explicitly recognized as the three key elements of the city's smartness, in line with the broad approach to a smart discourse. In this way, the local government tried to reflect diverse interests and needs in the design of a shared vision.

The local government advocated the smartness orientation by social suasion and direct involvement of several groups of actors (political work), consistently with the emerging call for collaboration. Indeed, the local government called for the creation of working groups where interested actors may participate to contribute to the development of policies and projects. To institutionalize the involvement of multiple actors, the local government established foundations and public-private partnerships, to which the specific role of developing and supporting collaborations was assigned. In particular, the political work in which the local government was engaged in was designed to align the foundations' interests with the politicians' interest in sustaining a smartness orientation and thus creating an appropriate context for developing smart city policies. Specifically, politicians were strongly interested in obtaining legitimacy from citizens, which determined which smart city projects would be implemented:

"Has this project an impact on the community? What will citizens say to me in 4 years?" (Municipality- Interviewee D).

Then, it was on the part of the foundations and public-private partnerships to carry out the technical work needed to design and implement smart city initiatives in a model of collaborative governance. These actors were expected to specify a model to follow. Hence, they were initially involved in running the planning phase of a master plan, which identified the primary areas in which to invest. Launched in 2013, the master plan was the first collaborative effort of the municipality in concert with several other key actors to identify action priorities and design potential projects. Indeed, the master plan was the result of a collaborative process that involved 65 actors and more than 300 people from public and private organizations as universities, research centres, associations, and foundations. The master plan 
was then adopted as an official planning document in 2014, establishing the groundwork for the development of smart projects. The Foundation Alfa played a key role as a technical partner of the local government in planning the development of the smart city project and as a supporter of collaborative processes, nevertheless providing resources in terms of staff and technology for developing smart city initiatives (technical work). The master plan initially acted as a plan to build collaboration, identify shared interests and define common objectives and purposes; however, the plan was not updated over the years and its implementation was difficult.

In addition, the internal unit in charge of smart city projects was expected to act as the coordinator (technical work):

"We have the role of governance and thus to bring together actors inside and outside the public administrations, who allow us to realize innovative projects in different sectors" (Municipality- Interviewee B).

However, the work of the local government has been complicated by the lack of a standardized model:

"The relationships with the municipality change continuously. It is a difficult aspect.

There is not a unique valid or standardized model. We work in an ever-evolving context, and we need to reinvent ourselves every time" (PPP- Interviewee G).

Further, the last political elections represented a drastic change in the system and influenced the manner of governing and the strategic approach to the smartness policy. Compared with the initial approach, the content of policies and the organization of the administration concerning smart initiatives changed after the elections. Thus, the political changes modified the political dynamics and specifically created some initial tensions internal to the local government.

Thus, the technical work of the institutional actors involved has been challenged and constrained by the lack of clear procedures and arrangements, by the political changes, and by the complexity of smart city initiatives, starting from the lack of a cultural framework guiding all the actors towards a common perspective.

As shown by the lack of a shared approach to smart city, the actors were not engaged in a proper cultural work to render innovation normatively desirable by all actors and build the required shared motivation. The different interpretations across actors have resulted in internal conflict and scepticism, as demonstrated by the following quotes:

"There is a lot of rhetoric... it seems that the technology can solve everything" (Municipality - Interviewee C).

"Also in this field there are phases, trends ..." (Municipality- Interviewee F). 
This context lacking cultural work challenges the attempts to make the proposed changes appear appealing to a wide audience.

Table 1 summarizes these findings.

- Insert Table 1 around here -

\section{DISCUSSION}

Findings point out that the environmental pressures towards the adoption of sustainable policies as a component of smart city have acted through the political and cultural work of the European Commission and, to a lesser extent, of the central government, which have influenced the government decisions by setting specific policies and funding initiatives in support of smart city initiatives. Then, the attention paid to these issues by consulting agencies and the higher awareness of the society have reinforced the relevance of a smart discourse. These institutional pressures, the need for resources and the sharing of problems and interests have encouraged different actors to collaborate to invest in smart city initiatives and these power-resource asymmetries have thus been incentives for participation (Ansell and Gash, 2008). Becoming smart has been perceived as being strongly dependent on building collaboration and partnerships, but more than an ideological purpose, these collaborations have been instrumental (Huxham et al., 2000) in obtaining the needed resources to develop smart city policies.

Therefore, the local government has been engaged in significant political work through which it has identified the needed leaders, conferred roles and responsibilities, promoted the development of smart city agenda and tried to align the actors towards a smart city discourse by collaborating and exploiting existing funding opportunities. The most powerful actor in activating the smart discourse has been the local government. Local councilors and public managers have felt the pressures to respond to national and international expectations and have been interested in improving the public administration image and performance.

However, then, the technical work has been mainly delegated and carried out by specific units inside the municipality and by ad-hoc established foundations and public-private partnerships. They have been expected to play an institutional role in leading the technical work, defining and coordinating smart city initiatives, supporting collaborations. However, despite the efforts put in elaborating shared agenda and master plan, and launching several sectoral initiatives, the governance of the collaborations has lacked clear institutional structure and arrangements, also because of a lack of proper political work in this regard. The wide array of actors involved in the governance of a smart city have intertwined through many different 
channels and procedures, making the relationships across the actors challenging. In practice, collaborations and partnerships have assumed quite different features, ranging from more formalized approaches under the control of the EC to more flexible mechanisms. These latter cases, in particular, demonstrate the challenges stemming from the model of collaborative governance in place.

According to Emerson et al. (2012), internal authority structures are more complex in collaborative governance than in hierarchical and stable structures. This phenomenon has in fact represented a challenge in the context under analysis, where the collaborative dynamics have been characterized by a fragmented governance, with insufficient capacity for joint action and low shared commitment, which influence one another reciprocally. Indeed, the political work conducted in this context by the local government and the technical work primarily conducted by foundations, public-private partnerships and the municipality's smart city unit, have not been integrated with the cultural work required to create widespread and shared commitment.

Figure 1 graphically depicts the overall considerations stemming from the analysis of institutional work carried out by multiple actors in the construction of a smart city collaborative governance model, where the arrows defining the collaborative dynamics show the institutional works linking the different actors.

- Insert Figure 1 around here -

In summary, smart city is a mission that can be realized by several actors working collectively and contributing to transforming a city by employing their specific knowledge and skills, since each participant has distinctive features both in terms of competence and knowledge and in terms of organizational mission and responsibilities (Bardach, 2001). Collaborative governance emerges as a needed and instrumental approach, where the contributions of different actors engaged in diverse activities at multi-levels determine a complex governance structure (Peters and Pierre, 2003). Indeed, multiple actors have been involved in the smart city, resulting in a complex governance structure. The several actors with different skills are needed to work in parallel and the involvement of multiple actors implies the need of a coordination among them and their different works (Perkman and Spicer, 2008). In this regard, the research provides key insights into the role played by different institutional works in the smart city context, explaining the consequent governance model. 
Firstly, inadequate and insufficient works, as demonstrated by the lack of proper cultural work, hinder the effective realization of the planned smart city initiatives. If changes brought to the institutional arrangements, for instance by creating new bodies, are not accompanied by cultural works, they become insufficient. In fact, an insufficient cultural work does not allow to set what new smart policies mean for the actors. Cultural work tends to be specialized, meaning that it needs to be performed by specialized people (Cloutier et al., 2015). However, the findings show that the limitation of this work to a strict range of actors in more powerful positions leads to the fact that ideas are not necessarily widely communicated and spread.

Secondly, the research findings identify a lack of support and coordination among the different works, as shown by the impact of current political and technical work on capacity for joint action. Their interaction and mutual reinforcement may be a condition for their effectiveness (Cloutier et al., 2015), but on the contrary the findings have shown that the capacity for joint action has been undermined not only by the lack of proper cultural works but also by tensions between political and technical works. On the one hand, the local government has tried to retain its leading role in the implementation and management of smart initiatives, both directly or indirectly through appropriate political work designed to control the other adhoc established organizations. On the other hand, the technical work has been fragmented among different actors with limited coordination. Further, since smart city initiatives are perceived only as a part of the broader range of activities of a municipality, their management becomes challenging for the local government if not well integrated within the comprehensive set of tasks to perform. In this context, the governance issues appear to have been underestimated by the actors involved and thus underdeveloped.

\section{CONCLUSIONS}

The present study investigated the collaborative governance model of a smart city in the north of Italy, Turin, and the institutional work conducted in this context by several key actors (Emerson et al., 2012; Lawrence et al., 2013). Although governance has been recognized as a crucial factor in the field of smart cities and the connotation of being smart has been assimilated into the realization of collaborative governance mechanisms (Albino, 2015; Chourabi et al., 2012; Moss Kanter and Litow, 2009; Nam and Pardo, 2014; Scholl and Scholl, 2014), many aspects in this area have been deeply underexplored (Bolivar, 2015; Pereira et al., 2017). Hence, the current research contributes to the body of knowledge on smart cities by adopting a public management perspective and providing new insights into a phenomenon scarcely studied. 
Particularly, the study investigates how and why the different institutional works engaged by multiple actors explain the way in which collaborative governance can be constructed and work in the smart city context. By studying the ways in which actors perform institutional works to fulfil their role and achieve their interests, the research contributes to develop the understanding of governance in smart city context.

The results achieved give the opportunity to support the considerations about the relevance of collaborations in making a city smart (Caragliu et al., 2011; Giffinger et al., 2007; Meijer and Bolivar, 2016), thus potentially identifying in collaborative governance a smart city governance model. Particularly, findings show that collaborations are needed both in the planning phase in order to set shared objectives and design agreed plan, and in the implementation phase, to carry out the projects. The results also extend and deepen the body of knowledge demonstrating that the way in which this governance model can be constructed and work is influenced by the institutional work carried out by multiple actors. In this regard, although it does not exist a best practice or a model that can fit every context, findings show the need and relevance of overcoming a bureaucratic model built only on the local government. Although the local government appears to be still a leading actor, multiple other actors, as foundations, associations, and private organizations, participate actively and influence how the model of collaborative governance is constructed and work by contributing with their resources and know-how. However, to make a smart city collaborative governance model succeed over time, not only the works made by the different actors need to be coordinated among them, but also different types of work must be performed by the same actor. Leading actors, as politicians and hoc-foundations, need to carry out not only political or technical works, but also cultural work designed to build the needed shared motivation and guarantee an adequate and aligned capacity for action. Although there is no "optimal formula" for harmonizing competing interests and overcoming fragmented government structures, flexibility and adaptation have been considered key factors for success (Christensen et al., 2016). However, as findings show, also flexibility and adaptation require guidelines and rules to manage uncertainty and share responsibilities, otherwise the wide arrays of dynamics can make the governance fragmented and less effective.

Therefore, although collaborative governance has been recognized as a useful tool to support a smart city, its constitutive elements have led to new challenges and problems because not properly supported by institutional actors' work. From a practical perspective, this has several implications. The assignment of specific tasks to actors may redefine the equilibrium and the relationships among them, requiring additional political efforts to manage 
responsibilities and guarantee an adequate structure. Both local government actors and the other actors involved in collaboration and partnerships should pay more attention to formally defining rules and procedures that can support the management of collaboration, guarantee their control and measure their performance by delineating clear responsibilities and incentives. Indeed, as stemming from the findings, there has been the recognition of the lack of clear and stable procedural arrangements and accountability boundaries, creating a feeling of confusion rather than motivation.

Above all, in light of the numerous collective actors involved, it is important to conduct efficient cultural work to guarantee an agreed-upon approach to a smartness orientation, facilitating shared motivation, and to increase the legitimacy of smart city initiatives through the involvement of legitimate actors. Therefore, it is crucially relevant to guarantee the involvement and representation of different interests from the initial planning of agenda and activities.

This study emphasizes the need to analyse collaborative governance's implications in the new public sector (Emerson et al., 2012; Emerson and Nabatchi, 2015; Mejier and Bolivar, 2016). In light of the recent reforms inspiring the public sector, as NPG, collaborative forms of governing are strongly encouraged but require appropriate management. The potential effect of such an approach in an innovative but challenging context such as that of a smart city calls for further investigation to go beyond talks and achieve desired expectations. Future research may adopt an actor-perspective and deepen the analysis of how multiple actors, including less powerful actors, can be involved in the definition and implementation of smart city initiatives through collaboration. Although collaborations are instrumental to make a city smart, they can determine new challenges and problems that, if not properly addressed, may undermine the smartness of the model.

\section{REFERENCES}

Albino, V., Berardi, U., and Dangelico, R. M. (2015), "Smart cities: Definitions, dimensions, performance, and initiatives", Journal of Urban Technology, Vol.22 No.1, pp. 321.

Angelidou, M. (2014), "Smart city policies: A spatial approach", Cities, Vol.41, S3-S11.

Ansell, C. and Gash, A. (2008), "Collaborative governance in theory and practice", Journal of Public Administration Research and Theory, Vol.18 No.4, pp. 543-571.

Anthopoulos, L. (2017), "Smart utopia VS smart reality: Learning by experience from 10 smart city cases", Cities, Vol.63, pp. 128-148. 
Bakıc1, T., Almirall, E., and Wareham, J. (2013), "A smart city initiative: the case of Barcelona", Journal of the Knowledge Economy, Vol.4 No.2, pp. 135-148.

Bardach, E. (2001), "Developmental dynamics: Interagency collaboration as an emergent phenomenon", Journal of Public Administration Research and Theory, Vol.11 No.2, pp. 149164.

Bartenberger, M. and Grubmüller, V. (2014), "The enabling effects of open government data on collaborative governance in smart city contexts", Journal of e-democracy, Vol.6 No.1, pp. 36-48.

Bătăgan, L. (2011), "Smart cities and sustainability models", Informatica Economică, Vol.15 No.3, pp. 80-87.

Benford, R. D. and Snow, D. A. (2000), "Framing Processes and Social Movements: An Overview and Assessment", Annual Review of Sociology, Vol.26, pp. 611-639.

Berry, C. and Glaeser, E. (2005), "The divergence of human capital levels across cities”, Papers in regional science, Vol.84 No.3, pp. 407-444.

Bifulco, F., Tregua, M., Amitrano, C., and D'Auria, A. (2016), "ICT and sustainability in smart cities management", International Journal of Public Sector Management, Vol.29 No.2, pp. 132-147.

Bolívar, M. (2015), "Smart cities: Big cities, complex governance?", Bolívar, M. (Ed.), Transforming city governments for successful smart cities, Springer, Cham, pp. 1-7.

Bommert, B. (2010), "Collaborative innovation in the public sector", International public management review, Vol.11 No.1, pp. 15-33.

Brorström, S. (2015), "Implementing innovative ideas in a city: good solutions on paper but not in practice?", International Journal of Public Sector Management, Vol.28 No.3, pp. 166-180.

Bryson, J. M., Crosby, B. C., and Stone, M. M. (2006), "The design and implementation of Cross-Sector collaborations: Propositions from the literature", Public administration review, Vol.66, pp. 44-55.

Caragliu, A., Del Bo, C., and Nijkamp, P. (2011), "Smart cities in Europe", Journal of Urban Technology, Vol.18 No.2, pp. 65-82.

Cocchia, A. (2014), "Smart and digital city: A systematic literature review”, Dameri, R. and Rosenthal-Sabroux, C. (Eds.), Smart city, Springer, Cham, pp. 13-43.

Chourabi, H., et al. (2012), "Understanding smart cities: An integrative framework", in System Science (HICSS), 2012 45th Hawaii International Conference on, IEEE, pp. 2289- 2297. 
Christensen, T. and Lægreid, P. (2007), "The whole-of-government approach to public sector reform", Public Administration Review, Vol. 67 No.6, pp. 1059-1066.

Christensen, T., Lægreid, P., and Rykkja, L. H. (2016), "Organizing for crisis management: building governance capacity and legitimacy", Public Administration Review, Vol.76 No.6, pp. 887-897.

Cloutier, C., Denis, J. L., Langley, A., and Lamothe, L. (2015). "Agency at the managerial interface: Public sector reform as institutional work", Journal of Public Administration Research and Theory, Vol.26 No.2, pp. 259-276.

Coe, A., Paquet, G., and Roy, J. (2001), "E-governance and smart communities: a social learning challenge”, Social science computer review, Vol.19 No.1, pp. 80-93.

Crivello, S. (2015). "Urban policy mobilities: the case of Turin as a smart city", European Planning Studies, Vol.23 No.5, pp. 909-921.

Eger, J. M. (2009). "Smart growth, smart cities, and the crisis at the pump a worldwide phenomenon", I-Ways, Vol.32 No.1, pp. 47-53.

Emerson, K. and Nabatchi, T. (2015), "Evaluating the productivity of collaborative governance regimes: a performance matrix", Public Performance and Management Review, Vol.38 No.4, pp. 717-747.

Emerson, K., Nabatchi, T., and Balogh, S. (2012), “An integrative framework for collaborative governance", Journal of Public Administration Research and Theory, Vol.22 No.1, pp. 1-29.

European Parliament, (2014), Mapping Smart Cities in the EU.

EY, (2016), Italia Smart. Rapporto Smart City Index 2016.

Flyvbjerg, B. (2006), "Five misunderstandings about case-study research", Qualitative inquiry, Vol.12 No.2, pp. 219-245.

Fu, S. (2007), "Smart café cities: Testing human capital externalities in the Boston metropolitan area", Journal of Urban Economics, Vol.61 No.1, pp. 86-111.

Giffinger, R. et al. (2007), "City-ranking of European medium-sized cities”, Cent. Reg. Sci, Vienna UT.

Grossi, G. and Pianezzi, D. (2017), "Smart cities: Utopia or neoliberal ideology?", Cities, Vol.69, pp. 79-85.

Huxham, C. et al. (2000), "The challenge of collaborative governance", Public Management an International Journal of Research and Theory, Vol.2 No.3, pp. 337-358.

Hwang, H., and Colyvas, J. A. (2011). "Problematizing actors and institutions in institutional work", Journal of Management Inquiry, Vol.20 No.1, pp. 62-66. 
Moss Kanter, R. and Litow, S. (2009), "Informed and interconnected: A manifesto for smarter cities", working paper, Harvard Business School, 15 June.

Kickbusch, I. and Gleicher, D. (2012), Governance for health in the 21st century, Copenhagen: WHO Regional Office for Europe.

Lawrence, T., Leca, B., and Zilber, T. (2013), "Institutional work: Current research, new directions and overlooked issues", Organization Studies, Vol.34 No.8, pp. 1023-1033.

Lawrence, T., Suddaby, R., and Leca, B. (2011), "Institutional work: Refocusing institutional studies of organization", Journal of management inquiry, Vol.20 No.1, pp. 52-58.

Lawrence, T. and Suddaby, R. (2006), "Institutions and Institutional Work", Clegg, S., Lawrence, T., and Nord, W. (Eds.), Handbook of Organization Studies, Sage, London, pp. 215254.

Lombardi, P. et al. (2012), "Modelling the smart city performance", Innovation: The European Journal of Social Science Research, Vol.25 No.2, pp. 137-149.

Meijer, A. and Bolívar, M. (2016), "Governing the smart city: a review of the literature on smart urban governance", International Review of Administrative Sciences, Vol.82 No.2, pp. $392-408$.

Michelucci, F. and De Marco, A. (2017), "Smart communities inside local governments: a pie in the sky?", International Journal of Public Sector Management, Vol.30 No.1, pp. 2-14.

Mora, L., Bolici, R., and Deakin, M. (2017), "The first two decades of smart-city research: A bibliometric analysis", Journal of Urban Technology, Vol.24 No.1, pp. 3-27.

Nam, T. and Pardo, T. A. (2014), "The changing face of a city government: A case study of Philly311", Government Information Quarterly, Vol.31, pp. S1-S9.

Osborne, S. (2010), The new public governance: Emerging perspectives on the theory and practice of public governance, Routledge, Oxon.

Paskaleva, K. (2011), "The smart city: A nexus for open innovation?", Intelligent Buildings Internationali, Vol.3 No.3, pp. 153-171.

Pereira, G. et al. (2017), "Increasing collaboration and participation in smart city governance: a cross-case analysis of smart city initiatives", Information Technology for Development, Vol.23 No.3, pp. 526-553.

Perkmann, M. and Spicer, A. (2008), "How are management fashions institutionalized? The role of institutional work", Human Relations, Vol.61 No.6, pp. 811-844.

Peters, B. G. and Pierre, J. (2001), "Developments in intergovernmental relations: towards multi-level governance", Policy and Politics, Vol.29 No.2, p. 131. 
Ryan, B., Scapens, R. W., and Theobald, M. (2002). Research method and methodology in finance and accounting.

Scholl, H. and Scholl, M. (2014), "Smart governance: A roadmap for research and practice", iConference 2014 Proceedings, doi:10.9776/14060.

Seo, M. G., and Creed, W. D. (2002). "Institutional contradictions, praxis, and institutional change: A dialectical perspective", Academy of management review, Vol.27 No.2, pp. 222-247.

Sørensen, E. and Torfing, J. (2012), "Introduction: Collaborative innovation in the public sector”, Innovation Journal, Vol.17 No.1, pp. 1-14.

Šiugždinienè, J., Gaulè, E., and Rauleckas, R. (2017), "In search of smart public governance: the case of Lithuania", International Review of Administrative Sciences, doi: 0020852317707814.

Torfing, J. and Triantafillou, P. (2013), "What's in a name? Grasping new public governance as a political-administrative system", International Review of Public Administration, Vol.18 No.2, pp. 9-25.

Vanolo, A. (2014), "Smartmentality: The smart city as disciplinary strategy", Urban Studies, Vol.51 No.5, pp. 883-898.

Yin, R. (2013), Case study research: Design and methods, Sage publications, Thousand Oaks. 
Table 2- Interviewees

\section{APPENDIX 1}

\section{Insert here}

\section{APPENDIX 2}

Interview outline

- Interviewee's previous experiences and current tasks and responsibilities

- Reasons for the vision of the smart city, its meaning and story of its development

- Main activities performed and actors involved

- Relationships across the actors and their management

- Reasons for collaborations

- Changes in the organizational structure and reasons

- Resources used

- What has worked and what has not

- Main outputs

\section{APPENDIX 3}

Table 3 - Collaborative governance in practice

Insert here 
Table 1 - The institutional work of multiple actors

\begin{tabular}{|c|c|}
\hline ACTORS & INSTITUTIONAL WORK \\
\hline $\begin{array}{l}\text { European Commission and central } \\
\text { government }\end{array}$ & $\begin{array}{l}\text { Political work } \\
\text { - Policy agenda on the topic of smart city } \\
\text { Cultural work } \\
\text { - Attempts to provide normative references to } \\
\text { the new policies making them desirable }\end{array}$ \\
\hline Local government - politicians & $\begin{array}{l}\text { Political work } \\
\text { - Assignment of roles and responsibilities to } \\
\text { new ad hoc established authorities } \\
\text { (foundations) } \\
\text { - Establishment of ad hoc internal units } \\
\text { designed to support smart city initiatives } \\
\text { - Calls for a Master Plan Work Group } \\
\text { involving several actors interested in the } \\
\text { topic } \\
\text { Cultural work } \\
\text { - Attempts to conduct persuasive acts } \\
\text { convincing other actors to collaborate by } \\
\text { elaborating a shared vision }\end{array}$ \\
\hline Local government- managers & $\begin{array}{l}\text { Technical work } \\
\text { - Unit in charge of coordinating the smart city } \\
\text { initiatives } \\
\text { - Training courses on smart city }\end{array}$ \\
\hline $\begin{array}{l}\text { Foundations, public-private- } \\
\text { partnerships }\end{array}$ & $\begin{array}{l}\text { Technical work } \\
\text { - } \quad \text { Engagement in designing a model to follow } \\
\text { (i.e. smart city master plan) } \\
\text { - Joint elaboration of projects } \\
\text { - } \quad \text { Shared knowledge and resources }\end{array}$ \\
\hline
\end{tabular}


Figure 1. The institutional work of key actors in the collaborative governance model

\section{General System context}

\section{Resource needs}

Political, environmental and societal pressures

National \& European policies

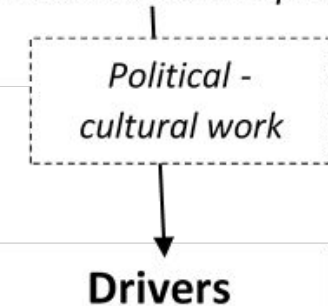

Opportunities for resources and ad-hoc actors to

be leaders
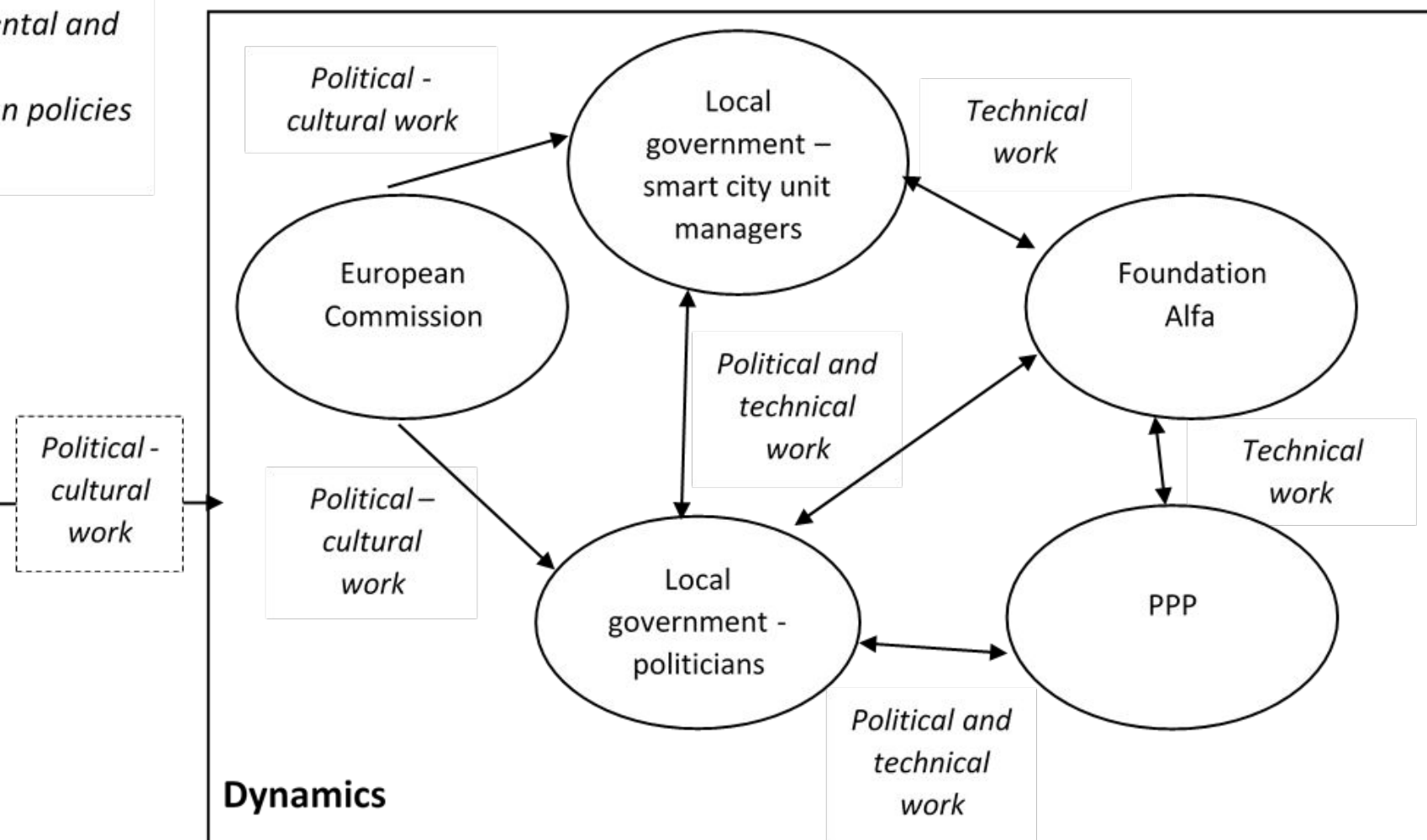

\section{Actions}

Plans, agenda, workshops, projects 
Table 2 - Interviewees

\begin{tabular}{|c|c|c|}
\hline INTERVIEWEE & ROLE & ORGANIZATION \\
\hline $\mathrm{A}$ & Manager - Smart City Unit & Municipality \\
\hline $\mathrm{B}$ & Manager - Smart City Unit & Municipality \\
\hline $\mathrm{C}$ & Manager - Smart City Unit & Municipality \\
\hline $\mathrm{D}$ & Politician & Municipality \\
\hline E & Manager - Sector Unit & Municipality \\
\hline $\mathrm{F}$ & $\begin{array}{l}\text { Manager - Organizational } \\
\text { Innovation Unit }\end{array}$ & Municipality \\
\hline $\mathrm{G}$ & Manager & $\begin{array}{l}\text { Public-Private-Partnership } \\
\text { (PPP) }\end{array}$ \\
\hline $\mathrm{H}$ & Manager & Private Organization \\
\hline I & Manager & Foundation Alfa \\
\hline
\end{tabular}


Table 3 - Collaborative governance in practice

\section{SYSTEM CONTEXT}

- Strong influence at the local level of national and European policy frameworks supporting the development of smart city initiatives (policy/legal framework)

- Limited financial resources at the local level

- Dependence of local government on national and European government decisions, for instance in terms of policies and funding (Power relations across levels of governments/organizations)

- Existence of relations between local government and other international organizations

\section{DRIVERS}

- Establishing foundations and public-private partnerships to play a leadership role and support collaborative governance

- Internal incentives, particularly opportunities for resources

- Perceived interdependence among actors to innovate but managed with difficulty

\section{DYNAMICS \\ Shared motivation}

- Tensions across levels of governments

- Lack of a widespread shared commitment towards a similar approach to the smart city

\section{Capacity for joint action}

- Lack of clear procedural arrangements; complex institutional structure

- Not always recognized and valorised shared knowledge

- Limited and fragmented resources (Funding, time, technical and logistical support, skills, expertise, etc.)

- Limited and controversial leadership, affected by political instability

\section{ACTIONS}

- Agreed-upon tasks realized individually by participants of joint projects (e.g., European projects)

- Tasks realized by multiple actors together (e.g., workshops, agenda, ...) 